\title{
A new role for browning as a redox and stress adaptive mechanism?
}

\author{
Yannick Jeanson, Audrey Carrière and Louis Casteilla* \\ UMR STROMALab, CNRS 5273, INSERM U1031, Université Toulouse III - Paul Sabatier, Toulouse, France
}

\section{OPEN ACCESS}

Edited by: Jun Wu,

University of Michigan, USA

Reviewed by:

Tae-Hwa Chun,

University of Michigan, USA

Jonathan R. Brestoff,

Perelman School of Medicine at the

University of Pennsylvania, USA

${ }^{*}$ Correspondence:

Louis Casteilla

louis.casteilla@inserm.fr

Specialty section:

This article was submitted to

Cellular Endocrinology,

a section of the

journal Frontiers in Endocrinology

Received: 23 June 2015

Accepted: 24 September 2015

Published: 09 October 2015

Citation:

Jeanson Y, Carrière A and Casteilla L

(2015) A new role for browning as a

redox and stress adaptive

mechanism?

Front. Endocrinol. 6:158.

doi: 10.3389/fendo.2015.00158
The worldwide epidemic of obesity and metabolic disorders is focusing the attention of the scientific community on white adipose tissue (WAT) and its biology. This tissue is characterized not only by its capability to change in size and shape but also by its heterogeneity and versatility. WAT can be converted into brown fat-like tissue according to different physiological and pathophysiological situations. The expression of uncoupling protein-1 in brown-like adipocytes changes their function from energy storage to energy dissipation. This plasticity, named browning, was recently rediscovered and convergent recent accounts, including in humans, have revived the idea of using these oxidative cells to fight against metabolic diseases. Furthermore, recent reports suggest that, beside the increased energy dissipation and thermogenesis that may have adverse effects in situations such as cancer-associated cachexia and massive burns, browning could be also considered as an adaptive stress response to high redox pressure and to major stress that could help to maintain tissue homeostasis and integrity. The aim of this review is to summarize the current knowledge concerning brown adipocytes and the browning process and also to explore unexpected putative role(s) for these cells. While it is important to find new browning inducers to limit energy stores and metabolic diseases, it also appears crucial to develop new browning inhibitors to limit adverse energy dissipation in wasting-associated syndromes.

Keywords: adipose tissue plasticity, adipocytes, redox, uncoupling protein-1, browning, stress

In the past, brown and white adipocytes were described as classically located in brown and white fat, respectively. Although these cells shared the name of adipocytes, their functions were traditionally opposed and those of brown adipocytes were strongly associated with the thermoregulation process and energy dissipation. The first discoveries that brown adipocytes could be detected in white fat were made in the 1980-1990s and revealed an unexpected plasticity of white adipose tissue (WAT), largely driven by $\beta 3$-agonist, at least in rodents (1-3) and dogs (4). Unfortunately, the lack of efficiency of $\beta 3$-agonist treatment in humans caused interest in this field to wane. However, in recent years, the rediscovery of uncoupling protein-1 (UCP1)-expressing cells in white fat together with the simultaneous demonstration of the presence of functional brown adipocytes in human adults have been accompanied by very new insights into the developmental origins of the different types of adipocytes. These ground breaking discoveries have completely changed our view on adipose tissue plasticity and generated great enthusiasm associated with a huge number of publications in the field, reporting unexpected results. The present review tries to summarize these recent findings and discusses new perspectives concerning unexpected roles and functions of UCP1-expressing cells. 


\section{WHITE ADIPOCYTES, BROWN ADIPOCYTES, AND ADIPOSE TISSUE PLASTICITY: A HISTORICAL PERSPECTIVE}

\section{White Adipocytes}

Mature white adipocytes play a fundamental role in energy homeostasis and constitute the main stores of energy in the form of triglycerides (5). They display variable size $(25-200 \mu \mathrm{m})$ and a unilocular morphology. In addition to their metabolic functions, white adipocytes have strong endocrine activity and secrete a variety of molecules commonly called adipokines, highlighting the fact that adipose tissue has interactions with other organs in the body (6). These cells are mainly localized in WAT, which are found at distinct anatomical sites. Subcutaneous and visceral fat pads (mesenteric, perigonadal, perirenal, etc.) are classically distinguished because the subcutaneous WAT has a protective action whereas the visceral fat pad is thought to be more deleterious in the development of obesity and related metabolic diseases (type II diabetes, cardiovascular disease, etc.) (7-9).

\section{Brown Adipocytes and UCP1 Expression}

Brown adipose tissue (BAT) contains brown adipocytes, which are smaller $(15-60 \mu \mathrm{m})$ than white adipocytes and have a multilocular morphology (5). Brown adipocytes are highly oxidative cells that release energy as heat $(10,11)$ thanks to their high mitochondrial content and to the expression of UCP1. This protein, inserted in the inner mitochondrial membrane, acts as a proton channel and uncouples the production of ATP by ATP synthase from respiratory chain functioning. This leads to the activation of catabolism and subsequent heat production. This non-shivering thermogenesis plays a key role in body temperature homeostasis $(10,11)$ as definitively demonstrated by UCP1-deficient mice, which are cold sensitive (12). Moreover, the presence of large amounts of BAT in species like sheep or hibernates, which require active thermogenesis to protect the new-born animals from cold exposure on a snow-covered pasture in spring or to emerge from hibernation, also argues that BAT evolved primarily to function as a thermogenic system to maintain body temperature $(11,13)$. BAT is more vascularized than WAT and is probably among the most vascularized tissues of the body (14). Such vascularization is required for the integrity of BAT. It was recently demonstrated that reducing the vasculature specifically in adipose tissues induced the whitening of BAT (15). In a temperate environment, UCP1 is inhibited by di- and triphosphate nucleotides. During cold exposure, UCP1 is strongly and quickly activated by the sympathetic nervous system (SNS) (16). The local release of noradrenaline in BAT activates lipolysis, which induces the release of free fatty acids. These constitute not only oxidative substrates for brown adipocytes but also potent activators of UCP1 (17-19). The same adrenergic stimulus up-regulates the expression of UCP1 at the transcriptional level via activation of the PKA-p38 mitogen-activated protein kinase signaling pathway that induces the phosphorylation and activation of molecular transactivators of UCP1 $(19,20)$. With increasing time of cold exposure, SNS triggers a trophic response through activation of mitochondriogenesis that also contributes to the increase of the global thermogenic capacity of brown adipocytes (21). Recently, noradrenaline has also been shown to induce the phosphorylation of dynamin-related protein-1, which induces the fragmentation of brown adipocyte mitochondria. This fragmentation promotes uncoupling and mitochondrial depolarization (22). Lastly, in addition to the activation of the thermogenic program of mature brown adipocytes, noradrenaline also induces the proliferation of brown progenitors through the stimulation of $\beta 1$-adrenergic receptors and their differentiation (23).

In addition to their role in maintaining body temperature, brown fat cells possess strong oxidative potential and can thus also burn excessive calories (11, 24-26). Transplantation of BAT into the visceral cavity of mice fed with a high-fat diet or having the ob/ob genetic background increases glucose tolerance and improves insulin sensitivity $(26,27)$. However, UCP1-deficient mice are not obese when kept at room temperature $\left(21^{\circ} \mathrm{C}\right)(12)$. The onset of obesity is only observed when these mice are housed at thermal neutrality, exempt from any thermal stress (28). These findings underscore the importance of thermogenesis in the energy balance of homeothermic animals and can explain the different relative importance of diet-induced thermogenesis related to BAT activity according to the developmental status or the species (29). Because of their small size, rodents and many new-born mammals are permanently in thermogenic deficit, which leads to low grade but permanent BAT activation. Despite these limitations, when brown fat cells are stimulated, they exhibit properties that offer hope of new therapies as the cells constitute putative targets in the fight against metabolic diseases such as diabetes and obesity (30).

The beneficial effects of brown adipocytes on energy metabolism are also due to their endocrine/paracrine activity (31). It has long been known that brown adipocytes release triiodothyronine from thyroxine by their deiodase activity, thus stimulating their thermogenic capacity (32). More recently, the secretion of fibroblast growth factor-21 (FGF21), besides vascular endothelial growth factor, fibroblast growth factor-2, interleukin-6, and neural growth factor $(31,33-35)$, has been attracting much attention. High levels of FGF21, a protein originally known to be produced by the liver in response to fasting, are produced and secreted into the bloodstream by BAT, especially during thermogenic activation (36). FGF21 acts on many tissues, including WAT, the liver, pancreas, heart, or central nervous system (31). Furthermore, some adipokines, such as leptin, adiponectin, and resistin, formerly recognized as specifically secreted by white adipocytes $(37,38)$, are also secreted by brown adipocytes. By analogy with the term "adipokines" for proteins secreted by white adipocytes, molecules secreted by brown adipocytes have sometimes been referred to as "batokines" $(26,31)$.

Until the discovery of a third type of adipocyte, things were very simple and focused on UCP1 only: the absence or presence of UCP1 in an adipocyte defined the white or brown phenotype, respectively. Thus, many studies investigated the control of UCP1 gene expression and first focused on catecholamines and thiiodothyronine pathways $(19,39)$. In addition to cAMPdependent responsive element binding protein and thyroid hormone receptor, other molecules, including CCAAT/enhancer 
binding protein- $\beta$ transcription factor, retinoic acid receptor, activating transcription factor-2, and peroxisome proliferatoractivated receptors gamma and alpha (PPAR $\gamma$ and PPAR $\alpha$ ), strongly up-regulate the expression of UCP1 at transcriptional level $(40,41)$. Among all these regulatory proteins, PPAR $\gamma$ plays a pivotal role and mice having non-functional PPAR $\gamma$ exhibit brown adipocytes with a unilocular lipid droplet (looking like white adipocytes!) and a decrease in UCP1 expression after cold exposure (42). The presence of PPAR $\gamma$ agonists, such as the anti-diabetic agent rosiglitazone, is required for the expression of UCP1 in adipocytes differentiated in primary culture (43). Various co-regulators, such as peroxisome proliferator-activated receptor coactivator- $1 \alpha$ (PGC-1 $\alpha)$ and the positive regulatory domain containing-16 protein (PRDM16) are also crucial. The expression of PGC- $1 \alpha$ is regulated by the PKA pathway (44) and, in vitro as well as in vivo, overexpression of PGC- $1 \alpha$ induces the expression of UCP1 along with other mitochondrial genes (45-47). In the same manner, specific overexpression of PRDM16 in adipose tissue is sufficient to induce browning of visceral adipose tissue (48). Furthermore, beside phosphorylation events that tightly control the activity of transcription factors and co-regulators, $\mathrm{NAD}^{+}$-dependent deacetylase sirtuin-1 deacetylates PPAR $\gamma$ on two lysine residues, enabling PRDM16 recruitment and the subsequent activation of UCP1, in a rosiglitazone-dependent manner (49). It should be noted that none of these molecular regulators are specific to brown adipocytes and UCP1 expression. In particular, PPAR $\gamma$, which appears crucial for the expression of UCP1, also has the great disadvantage of promoting white adipocyte differentiation (50).

\section{Adipose Tissue Plasticity: From Brown to Brite}

As early as 1984, Young et al. described the presence of UCP1expressing adipocytes in murine parametrial fat (1). This observation was more precisely described in later studies by Loncar (2) and Cousin et al. (3). Such apparent tissue plasticity was found to be strongly promoted after cold exposure or $\beta 3$-adrenergic agonist, including in dogs (4). The relative numbers of these cells varies according to the fat pad. Subcutaneous WAT is more likely to develop UCP1-expressing cells than other depots such as mesenteric and perigonadic WAT. We therefore proposed a gradient in the plasticity of the different white fat pads similar to that described for skeletal muscles, which are classified as glycolytic, oxidative, and mixed fiber (3). Two non-exclusive hypotheses could explain the emergence of UCP1-expressing adipocytes in WAT: de novo differentiation from progenitors and/or transdifferentiation of mature white into brown adipocytes (51). The hypothesis of transdifferentiation is supported by several findings demonstrating that there is neither an increase in DNA amount nor a process of preadipocyte proliferation during acute cold exposure in the peri-ovarian adipose tissue (52).

It is noteworthy that, for decades, UCP1-expressing cells in white fat were considered as comparable to the classical brown adipocytes present in a typical BAT depot, i.e., the interscapular BAT. However, recent findings have strongly challenged this view and demonstrated that these cells have distinct gene expression profiles $(53,54)$ and different developmental origins (55-58). UCP1-expressing adipocytes in white fat thus constitute a third type of adipocytes, which have recently been named beige or brite (brown in white) adipocytes $(43,54,59,60)$. The development of these cells in WAT has been termed the browning process.

\section{A NEW LOOK ON WAT HETEROGENEITY AND PLASTICITY: ADIPOCYTES OF ALL COLORS AND ORIGINS}

It was long thought that white and brown adipocytes had a common progenitor but recent works have challenged this idea. A first step came with the proposal that classical brown adipocytes, and not brite adipocytes, derived from the paraxial mesoderm, particularly the dermomyotome, and that they originated from a precursor expressing myogenic transcription factor-5 (Myf5) (55). The commitment of the bipotent progenitor to the brown phenotype is controlled by members of the TGF- $\beta$ superfamily, such as BMP7 and the PRDM16-C/EBP $\beta$ transcriptional complex, which induce the expression of PPAR $\gamma$ and PGC-1 $\alpha$ (41, $61,62)$. The common developmental origin of muscle cells and typical brown adipocytes is also supported by their very similar transcriptional signature $(53,54)$ and the old observation of the presence of glycogen stocks in brown adipocytes $(63,64)$. Furthermore, the demonstration that human skeletal muscle contains CD34 positive progenitor cells that can easily differentiate into brown adipocytes is another argument in favor of the link between brown adipocytes and skeletal muscle cells (65). The common origin of both types of cells could also be related to their metabolic activities, which are very close from a bioenergetics point of view. Shivering thermogenesis in muscle corresponds to the implementation of a futile cycle with a high rate of ATP synthesis associated with a high rate of ATP consumption by contraction processes. The resulting high oxidative catabolism dissipates a large amount of energy as heat. In this case, the functioning of ATP synthase resembles that of a mitochondrial proton channel such as UCP1. From a somewhat provocative point of view, brown adipocytes could be presented more as specialized muscle cells than as specialized adipocytes. Whatever the fate of such a hypothesis, this rather simplistic portrayal was quickly complicated and the developmental origin of the different types of adipocytes does not appear to be as simple as initially proposed. While brown adipocytes present in the interscapular BAT are thought to derive from Myf5-positive progenitors, those present in the brown perirenal and peri-aortic fat pads would originate from a Myf5-negative progenitor (56). Furthermore, some white and brite adipocytes could also emerge from Myf5-positive cells, according to the nature of fat deposits $(56,58)$. To increase the complexity further, it has been proposed that a subpopulation of brite adipocytes derives from smooth muscle cell (66).

Like the developmental origin, the cell mechanism(s) at the origin of the browning process in adults are not yet clear and are still widely debated. Consistently with the transdifferentiation hypothesis, a recent study using a transgenic mouse model with permanent or temporary staining of UCP1-expressing cells, has shown that some "phenotypically white" adipocytes can acquire 
a brite phenotype (i.e., displaying multilocular droplets together with UCP1 expression) after cold exposure (67). Conversely, when these mice were returned to $21^{\circ} \mathrm{C}$, the brite adipocytes returned to a white phenotype (i.e., unilocular droplet), reacquiring a brite phenotype after re-exposure to cold (67). In apparent opposition to this conclusion, another study has recently demonstrated that beige adipocytes arise from de novo differentiation of precursors (68). The browning mechanism would also rely on different cell mechanisms according to the nature of the fat pad. While UCP1-expressing adipocytes within subcutaneous WAT would arise from the transdifferentiation phenomenon, those from the epididymal fat pad would originate from the proliferation and the differentiation of progenitor cells $(69,70)$. Adding to this complexity, it should not be forgotten that non-stimulated brite adipocytes could have a phenotype very close to that of the white adipocyte. This phenotype homology could lead to a misinterpretation of browning as a white adipocyte transdifferentiation when it could simply correspond to the activation of inactive brite adipocytes. It is noteworthy that, whatever the intensity of the stimuli, some unilocular white cells are totally refractory to cell plasticity. This would also mean that different types of unilocular cells lacking UCP1 expression could co-exist inside the same fat pad.

The compilation of these findings shows the current confusion, which is probably due to the underestimated complexity of the system. It seems that there are several pathways and developmental origins that give rise to unilocular UCP1 negative adipocyte(s) and to multilocular UCP1 positive adipocyte(s), without anyone knowing if cells having a similar apparent phenotype have the same functions and carry out the same regulations. This also emphasizes the lack of relevant, robust tools to identify and distinguish the different types of adipocytes because the white adipocyte phenotype is defined by its lack of brite or brown adipocyte markers, which is clearly insufficient. Although a large number of markers specifically expressed in each type of adipocytes or precursors have been proposed from gene expression profiling of isolated white, brown, and brite adipocytes and/or from studies on whole adipose tissues, their validity is currently under investigation (71). This kind of approach does not really take account of the heterogeneity of cells inside the tissues. Even in conditions of browning such as cold exposure, brite adipocytes represent only a small proportion of the tissue cells and this can lead to a biased view grouping white and brite adipocytes together. It is therefore necessary to characterize the different adipocytes in homogeneous cell populations. Also, we cannot exclude the possibility that typical brown adipocytes could co-exist with brite adipocytes in the same white fat pad since brite adipocytes can co-exist with typical brown adipocytes in typical brown fat pad.

\section{UNEXPECTED BROWNING INDUCERS REVEAL PUTATIVE NEW ROLES FOR UCP1-EXPRESSING ADIPOCYTES}

After the old failure of $\beta 3$-agonist treatment in humans, the discovery of functional brown fat in adult humans has revived the research. Besides the adrenergic pathway that represents the ancestral and best described activator of UCP1 expression and in addition to thyroid hormones, several peptides have recently been identified as browning inducers or inhibitors that correspond to as many therapeutic targets. Several recent reviews summarize the different regulators of the browning process (41, 72-74). We decided to focus on the unexpected physiological or physio-pathological conditions recently found to regulate the browning process and that highlight putative new functions for these cells (Figure 1).

\section{Browning as an Adaptive Element in Redox Metabolism?}

While an increasing number of agents have been reported to stimulate browning as discussed, very few studies have investigated the role of the metabolic environment in the phenomenon. We recently demonstrated the unexpected role of redox metabolites, such as lactate, in the browning process. Lactate, which is a major product of anaerobic metabolism, promotes WAT browning through its transport by the monocarboxylate transporters (75). Lactate-induced browning is mediated by a change in the intracellular redox state (Figure 2). The transformation of lactate into pyruvate by lactate dehydrogenase $\mathrm{B}$ induces a higher $\mathrm{NADH} / \mathrm{NAD}^{+}$ratio and modulation of this ratio by different strategies modulates the expression of UCP1 (75). As, in turn, uncoupling the ATP production from the respiratory chain by high levels of UCP1 accelerates the oxidation of NADH by the complex I, we postulate that browning constitutes an adaptive mechanism to alleviate a strong redox pressure (75) (Figure 2). The increased expression of the lactate-importing transporter during activation of UCP1-expressing adipocytes, e.g., after cold exposure (75) suggests that lactate could also be used as a substrate by these cells. We postulate that, in the same way as for glucose and triglyceride homeostasis, UCP1-expressing cells could regulate plasma lactate levels and lactate metabolism. We propose that there is a redox regulatory loop where lactate induces a metabolic reprograming of adipocytes toward an uncoupled oxidative phenotype that, in turn, favors lactate consumption and dissipation.

This points to a totally new function for brite adipocytes and extends the role of lactate as a signaling molecule in the browning field. This signaling pathway could also be involved in the emergence of UCP1-expressing adipocytes in white fat during obesity. WAT is an important producer of lactate in physiological conditions $(76,77)$. It could be postulated that, in an obesity context where large adipocytes are hypoxic, they could locally produce large amounts of lactate that would stimulate the browning of neighboring white adipocytes and/or the recruitment of brite progenitors that promote energy dissipation (77). This link between browning and redox state is also emphasized by two recent studies, demonstrating that UCP1 expression is strongly controlled by different redox elements such as oxidative stress and antioxidant defenses. Sestrins, stress-inducible proteins that limit oxidative stress, inhibit UCP1 expression (78) while glutathione deficit, one of the key elements of the cytosolic antioxidant 


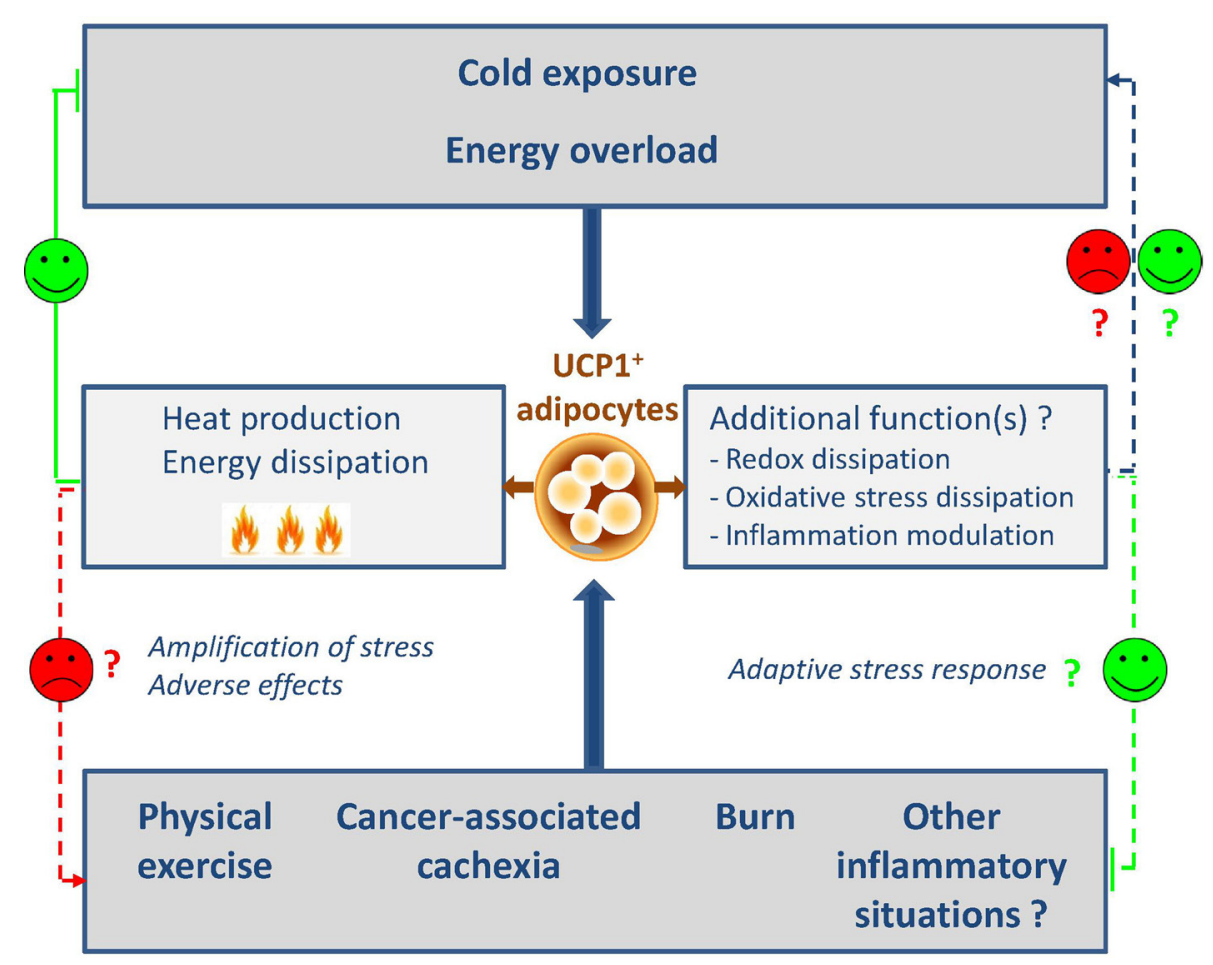

FIGURE 1 | Classic and new regulators of browning. The induction of browning is classically described after cold exposure or high-fat diet and leads to the generation of heat and energy dissipation. In this context, browning represents a relevant target to fight against metabolic diseases. More recently, unexpected physiological or physio-pathological situations were also described as new browning inducers. These findings shed the light on putative and unexpected roles of browning such as redox and oxidative stress dissipation and inflammation modulation. On the other hand, the automatic association with heat and energy dissipation could appear as adverse side effects that will be necessary to control. The design of browning antagonists will be then relevant.

defenses, increases it (79). Oxidative stress and redox state thus constitute new and important regulators of UCP1 expression.

\section{Browning as a Non-Specific Stress Response?}

Three unexpected physiological or pathophysiological situations were found to be associated with browning: exercise, cancerassociated cachexia, and burns. Before our findings, physical exercise had been shown to activate BAT and WAT browning $(80,81)$. In addition to IL-6 (82), two muscle-derived hormones, irisin and meteorin-like, are believed to mediate such effects $(80,83)$. The expression and the impact of irisin in humans have been strongly debated but its existence has been unequivocally demonstrated by a recent study using tandem mass spectrometry (84). Irisin is detectable in the blood of untrained persons during exercise or exposure to low temperatures $(84,85)$. While some studies have shown that irisin has no effect on the differentiation of human preadipocytes toward the brite phenotype (86), others have demonstrated that irisin activates the thermogenic activity of preadipocytes extracted from human neck (87). Additional signals, including lactate, whose plasma levels rise strongly during physical activity, could also contribute to exercise-induced UCP1 expression (75). The second situation, cachexia, is related to physiopathology associated with wasting syndromes, such as diabetes, sepsis, and cancer (88). It results in chronic inflammation and severe weight loss associated with atrophy of fat deposits and muscles. It is often associated with high plasma levels of lactate and usually precedes the death of the patient (89). Several studies have demonstrated that cachexia induced by the injection of cancer cells is associated with browning of WAT and an increase in energy expenditure (90-92). Inflammation and, especially, the production of interleukin- 6 play a key role in this phenomenon and the lack of interleukin- 6 receptor blocks browning induced by cancer cells (90). Parathyroid hormone-related protein may also mediate cancer-cell-induced browning of WAT (91). Lastly, in addition to exercise and cachexia, severe burns are associated with hypermetabolic response, hyperthermia, and browning in rodents and in humans $(93,94)$.

The role(s) of UCP1-expressing cells in these different conditions still remain to be unraveled. The fact that muscle contraction during exercise promotes the emergence and activation of energy-dissipating and thermogenic cells does not seem physiologically consistent with the energy conservation theory. This discrepancy would be explained if muscle-derived signals that induce browning could be shown to have evolved from shivering-related muscle contraction (87). In this scenario, WAT browning would represent a coherent and additive mechanism in thermoregulation promoted by shivering. For cachexia, associated browning could constitute an adaptive thermoregulatory 


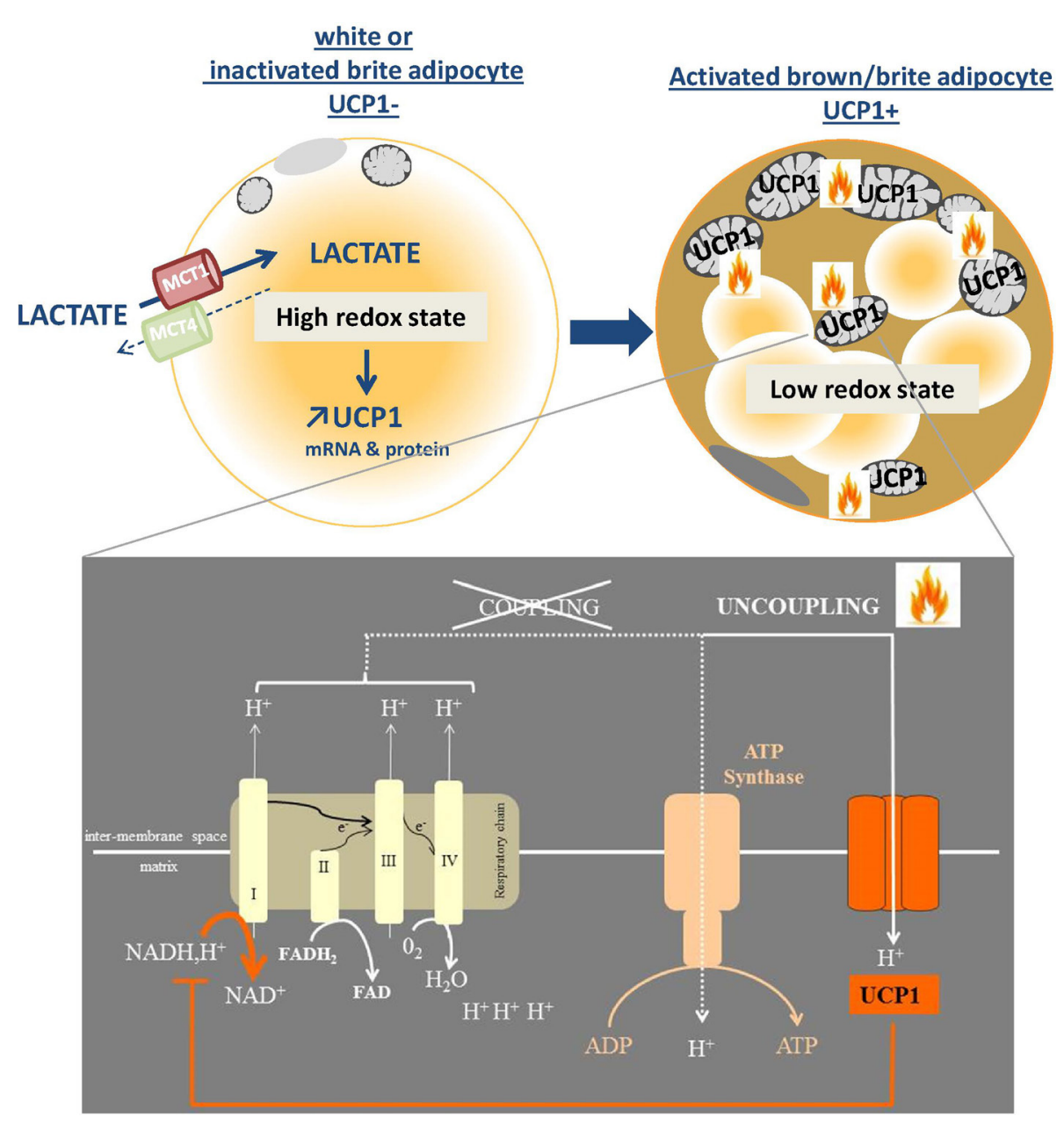

FIGURE 2 | Browning as a redox responsive mechanism. The import of lactate via the monocarboxylate transporter MCT1 is associated with a redox state (NADH/NAD) increase which, in turn, triggers the expression of browning genes including UCP1. The effect of activated UCP1, which is inserted into the inner mitochondrial membrane, is to uncouple the respiratory chain function from the ATP synthesis. The subsequent increase in oxidative metabolism generates heat and oxidizes reduced equivalents such as $\mathrm{NADH}$, which was at the origin of the up-regulated UCP1 expression.

response to fight against the hypothermia associated with the decrease of both fat insulation and heat-related muscle mass observed during cachexia. Addressing this issue would require these results to be reproduced at thermoneutrality, as illustrated by the study conducted by Champigny et al. in starving conditions (95). In this study, the authors found an up-regulation of UCP1 expression and brown adipocyte activation during starvation, which are physiologically inconsistent (95). In fact, starvationinduced UCP1 expression disappeared when mice were kept at thermoneutrality, suggesting that UCP1 up-regulation was an adaptive thermogenic response of rats to fight against the temperature deficit associated with starvation-induced torpor (95). Browning is always associated with thermoregulation responses in these situations but could have adverse metabolic effects that need to be controlled. For massive burn injury, browning would be triggered by the large stress release of catecholamine and inflammatory signals and would participate in the increase of the whole body metabolic rate (94). In fact, the role of inflammatory signals and cytokines on the browning process was first reported during cold exposure (96). Cyclooxygenase-2, whose expression is increased in WAT during cold exposure, is thought to trigger the browning process through the synthesis of prostaglandins E2 and I2 $(97,98)$. The link between prostaglandins and UCP1 is not new and it has been proposed that the natural ligand of PPAR $\gamma$ is prostaglandin PGJ2 (99). However, these results have been questioned following the recent publication of the opposite effect of prostaglandins E2 and F2 $\alpha$ on the expression of UCP1 (100). Surprisingly, immune cells are involved in cold-induced browning as eosinophils express and secrete interleukin-4 and interleukin-13, which recruit alternative M2 macrophages in the subcutaneous WAT during cold exposure (101). These macrophages secrete catecholamines that induce browning. The meteorin-like hormone secreted by both WAT and BAT during cold exposure or during physical exercise has the same 
effect on eosinophils (83). At the same time, another group has demonstrated that the activation by interleukin-33 of Group 2 innate lymphoid cells (ILC2s), known for their role in tissue remodeling, could also induce the recruitment of eosinophils via the release of interleukin-13 (102). ILC2s may also, in response to interleukin-33, produce and secrete methionine-enkephalin, a new browning inducer (103). Although all these mechanisms were discovered in the context of cold exposure, it is reasonable to speculate that any events able to activate ILC2s or eosinophils are able to promote browning. Together with the fact that interferon regulatory factor-4 controls UCP1 expression (104), these observations bring to light an undiscovered link between browning and inflammation/immunity.

The consequences of the apparition of UCP1-expressing cells in such inflammation- and injury-related scenarios currently remain poorly understood but it is noteworthy that the common point between all the situations is the notion of intense stress and inflammation. For this reason, with the limits concerning thermoregulation discussed previously and although these fields are evolving rapidly, we can already assume that browning could appear in any severe stress conditions. Whether these cells have positive or negative effects on such stress and loss of tissue homeostasis conditions is unknown (Figure 1). They could have adverse effects through increased energy dissipation in wasting syndromes and injury conditions but also could play positive roles through unexpected functions such as redox and oxidative stress dissipation, metabolite consumption, or even anti-inflammatory actions. This is an underexplored scientific area that will remain very open for the coming years.

\section{PERSPECTIVES IN HUMANS}

In humans, it has long been considered that BAT is only present in neonates, with some exceptions such as patients suffering from pheochromocytoma $(105,106)$ or workers exposed to cold temperatures (107). Mainly localized in the interscapular region like the main murine BAT depot, the BAT present in new-born babies enables heat to be produced to combat the thermal stress associated with birth. While this fat pad disappears rapidly and is absent in human adults like in adult sheep (13), some histological studies performed in the 1970s claimed that human adults possessed some brown fat deposits in additional zones, including around the kidney, heart, and adrenal gland, and along the aorta and carotid (108). However, these studies were unable to change the general opinion that human adults did not possess BAT. Recently, this view has been contradicted by medical imaging based on the measurement of glucose uptake (using 18-fluorodesoxyglucose associated with positron emission tomography-computed tomography) This approach, widely used in oncology to detect tumors, when associated with histological and immunocytochemistry studies, highlighted the presence of BAT in healthy human adults (109-112). The activity of BAT is inversely correlated with body mass index, suggesting that it could play a role in energy homeostasis (109-112). Given their high oxidative potential and their ability to consume nutrients such as glucose and triglycerides, brown adipocytes in humans possess very attractive properties for fighting against metabolic diseases, including type II diabetes and obesity (30). While molecular profiling studies have shown that human brown adipocytes are very similar to brite adipocytes described in mice $(59,113,114)$, some others claim that brown fat deposits in humans are made of a mixture of brown and brite adipocytes, the differential distributions of which appear to depend on their anatomical location, consistently with our previous remarks. In the neck region, brown adipocytes would be located deep within the tissues and brite adipocytes rather at the surface $(115,116)$. The search for brite progenitors in human WAT led to the discovery of bipotent (white and brite) progenitors that expressed the tissue non-specific alkaline phosphatase marker (117), while CD29 enabled the isolation of brown progenitors present in the deep regions of the human neck (118). Among the putative targets (72), we cannot ignore the $\beta 3$-adrenergic pathway. Although many efforts failed to find suitable compounds (119), new pharmacological and genetic studies have revealed that targeting this pathway could be efficient (120-122). While PPAR $\gamma$ is a very potent inducer of UCP1 expression, it also causes many side effects, including body weight gain and cardiovascular issues, that strongly impair its therapeutic use (50). One way to bypass this issue would be to design a selective PPAR modulator $(123,124)$. Recently, oral supplementation of the bile acid chenodeoxycholic acid has been shown to activate BAT and to increase whole body energy expenditure in humans, making bile acids attractive candidates for counteracting obesity and related metabolic diseases (125).

By contrast, recent works on inflammation and burns have also revealed the bad and the ugly of browning as previously described. While it is important to find new browning inducers to limit energy stores and metabolic diseases, it also appears crucial to develop new browning inhibitors to limit adverse energy dissipation in wasting-associated syndromes.

\section{CONCLUSION}

All these recent discoveries constitute a very active field attracting groups of scientists who are expert not only in metabolism but also in immunology, development, cancer, etc. This has shed new and unexpected light on brown and brite adipocytes and has already given original insights into the putative role of these cells. For the future, it is reasonable to speculate that the story is not finished because this field is now wide open and raises new questions and hypotheses, keeping in mind the key ancestral role of UCP1 in thermogenesis and bioenergetics.

\section{ACKNOWLEDGMENTS}

This work was supported by the EU FP7 project DIABAT (HEALTH-F2-2011-278373) and the EU FP7 project METABOSTEM (PCIG9-GA-2011-293720). 


\section{REFERENCES}

1. Young P, Arch JR, Ashwell M. Brown adipose tissue in the parametrial fat pad of the mouse. FEBS Lett (1984) 167(1):10-4. doi:10.1016/0014-5793(84)80822-4

2. Loncar D. Convertible adipose tissue in mice. Cell Tissue Res (1991) 266(1):149-61. doi:10.1007/BF00678721

3. Cousin B, Cinti S, Morroni M, Raimbault S, Ricquier D, Penicaud L, et al. Occurrence of brown adipocytes in rat white adipose tissue: molecular and morphological characterization. J Cell Sci (1992) 103:931-42.

4. Champigny O, Ricquier D, Blondel O, Mayers RM, Briscoe MG, Holloway BR. Beta 3-adrenergic receptor stimulation restores message and expression of brown-fat mitochondrial uncoupling protein in adult dogs. Proc Natl Acad Sci U S A (1991) 88(23):10774-7. doi:10.1073/pnas.88.23.10774

5. Rosen ED, Spiegelman BM. What we talk about when we talk about fat. Cell (2014) 156(1-2):20-44. doi:10.1016/j.cell.2013.12.012

6. Fasshauer M, Bluher M. Adipokines in health and disease. Trends Pharmacol Sci (2015) 36(7):461-70. doi:10.1016/j.tips.2015.04.014

7. Barrera C, Gatica A, Morgan C. Obese visceral adipose tissue grafted in lean mice can alter glucose homeostasis and energy efficiency. J Biol Regul Homeost Agents (2012) 26(3):411-7.

8. Karelis AD, St-Pierre DH, Conus F, Rabasa-Lhoret R, Poehlman ET. Metabolic and body composition factors in subgroups of obesity: what do we know? J Clin Endocrinol Metab (2004) 89(6):2569-75. doi:10.1210/jc.2004-0165

9. Tran TT, Yamamoto Y, Gesta S, Kahn CR. Beneficial effects of subcutaneous fat transplantation on metabolism. Cell Metab (2008) 7(5):410-20. doi:10.1016/j.cmet.2008.04.004

10. Nicholls DG, Locke RM. Thermogenic mechanisms in brown fat. Physiol Rev (1984) 64(1):1-64.

11. Himms-Hagen J. Brown adipose tissue thermogenesis: interdisciplinary studies. FASEB J (1990) 4(11):2890-8.

12. Enerback S, Jacobsson A, Simpson EM, Guerra C, Yamashita H, Harper ME, et al. Mice lacking mitochondrial uncoupling protein are cold-sensitive but not obese. Nature (1997) 387(6628):90-4. doi:10.1038/387090a0

13. Casteilla L, Champigny O, Bouillaud F, Robelin J, Ricquier D. Sequential changes in the expression of mitochondrial protein mRNA during the development of brown adipose tissue in bovine and ovine species. Sudden occurrence of uncoupling protein mRNA during embryogenesis and its disappearance after birth. Biochem J (1989) 257(3):665-71. doi:10.1042/ bj 2570665

14. Cao Y. Angiogenesis and vascular functions in modulation of obesity, adipose metabolism, and insulin sensitivity. Cell Metab (2013) 18(4):478-89. doi:10.1016/j.cmet.2013.08.008

15. Shimizu I, Aprahamian T, Kikuchi R, Shimizu A, Papanicolaou KN, MacLauchlan S, et al. Vascular rarefaction mediates whitening of brown fat in obesity. J Clin Invest (2014) 124(5):2099-112. doi:10.1172/JCI71643

16. Tupone D, Madden CJ, Morrison SF. Autonomic regulation of brown adipose tissue thermogenesis in health and disease: potential clinical applications for altering BAT thermogenesis. Front Neurosci (2014) 8:14. doi:10.3389/ fnins.2014.00014

17. Ricquier D. Uncoupling protein 1 of brown adipocytes, the only uncoupler: a historical perspective. Front Endocrinol (2011) 2:85. doi:10.3389/ fendo.2011.00085

18. Fedorenko A, Lishko PV, Kirichok Y. Mechanism of fatty-acid-dependent UCP1 uncoupling in brown fat mitochondria. Cell (2012) 151(2):400-13. doi:10.1016/j.cell.2012.09.010

19. Collins S. Beta-adrenoceptor signaling networks in adipocytes for recruiting stored fat and energy expenditure. Front Endocrinol (2011) 2:102. doi:10.3389/ fendo.2011.00102

20. Cao W, Daniel KW, Robidoux J, Puigserver P, Medvedev AV, Bai X, et al. p38 mitogen-activated protein kinase is the central regulator of cyclic AMPdependent transcription of the brown fat uncoupling protein 1 gene. Mol Cell Biol (2004) 24(7):3057-67. doi:10.1128/MCB.24.7.3057-3067.2004

21. Nechad M, Nedergaard J, Cannon B. Noradrenergic stimulation of mitochondriogenesis in brown adipocytes differentiating in culture. Am J Physiol (1987) 253(6 Pt 1):C889-94

22. Wikstrom JD, Mahdaviani K, Liesa M, Sereda SB, Si Y, Las G, et al. Hormoneinduced mitochondrial fission is utilized by brown adipocytes as an amplification pathway for energy expenditure. EMBO J (2014) 33(5):418-36. doi:10.1002/embj.201385014
23. Bronnikov G, Houstek J, Nedergaard J. Beta-adrenergic, cAMP-mediated stimulation of proliferation of brown fat cells in primary culture. Mediation via beta 1 but not via beta 3 adrenoceptors. J Biol Chem (1992) 267(3):2006-13.

24. Rothwell NJ, Stock MJ. A role for brown adipose tissue in diet-induced thermogenesis. Obes Res (1997) 5(6):650-6. doi:10.1002/j.1550-8528.1997. tb00591.x

25. Bartelt A, Bruns OT, Reimer R, Hohenberg H, Ittrich H, Peldschus K, et al. Brown adipose tissue activity controls triglyceride clearance. Nat Med (2011) 17(2):200-5. doi:10.1038/nm.2297

26. Stanford KI, Middelbeek RJ, Townsend KL, An D, Nygaard EB, Hitchcox $\mathrm{KM}$, et al. Brown adipose tissue regulates glucose homeostasis and insulin sensitivity. J Clin Invest (2013) 123(1):215-23. doi:10.1172/JCI62308

27. Liu X, Wang S, You Y, Meng M, Zheng Z, Dong M, et al. Brown adipose tissue transplantation reverses obesity in $\mathrm{Ob} / \mathrm{Ob}$ mice. Endocrinology (2015) 156(7):2461-9. doi:10.1210/en.2014-1598

28. Feldmann HM, Golozoubova V, Cannon B, Nedergaard J. UCP1 ablation induces obesity and abolishes diet-induced thermogenesis in mice exempt from thermal stress by living at thermoneutrality. Cell Metab (2009) 9(2):203-9. doi:10.1016/j.cmet.2008.12.014

29. Kozak LP. Brown fat and the myth of diet-induced thermogenesis. Cell Metab (2010) 11(4):263-7. doi:10.1016/j.cmet.2010.03.009

30. Algire C, Medrikova D, Herzig S. White and brown adipose stem cells: from signaling to clinical implications. Biochim Biophys Acta (2013) 1831(5):896904. doi:10.1016/j.bbalip.2012.10.001

31. Villarroya J, Cereijo R, Villarroya F. An endocrine role for brown adipose tissue? Am J Physiol Endocrinol Metab (2013) 305(5):E567-72. doi:10.1152/ ajpendo.00250.2013

32. de Jesus LA, Carvalho SD, Ribeiro MO, Schneider M, Kim SW, Harney JW, et al. The type 2 iodothyronine deiodinase is essential for adaptive thermogenesis in brown adipose tissue. J Clin Invest (2001) 108(9):1379-85. doi:10.1172/JCI200113803

33. Bagchi M, Kim LA, Boucher J, Walshe TE, Kahn CR, D’Amore PA. Vascular endothelial growth factor is important for brown adipose tissue development and maintenance. FASEB J (2013) 27(8):3257-71. doi:10.1096/fj.12-221812

34. Yamashita H, Sato N, Kizaki T, Oh-Ishi S, Segawa M, Saitoh D, et al. Norepinephrine stimulates the expression of fibroblast growth factor 2 in rat brown adipocyte primary culture. Cell Growth Differ (1995) 6(11):1457-62.

35. Hansen-Algenstaedt N, Algenstaedt P, Schaefer C, Hamann A, Wolfram $\mathrm{L}$, Cingoz G, et al. Neural driven angiogenesis by overexpression of nerve growth factor. Histochem Cell Biol (2006) 125(6):637-49. doi:10.1007/ s00418-005-0111-z

36. Hondares E, Iglesias R, Giralt A, Gonzalez FJ, Giralt M, Mampel T, et al. Thermogenic activation induces FGF21 expression and release in brown adipose tissue. J Biol Chem (2011) 286(15):12983-90. doi:10.1074/jbc. M110.215889

37. Buyse M, Viengchareun S, Bado A, Lombes M. Insulin and glucocorticoids differentially regulate leptin transcription and secretion in brown adipocytes. FASEB J (2001) 15(8):1357-66. doi:10.1096/f.00-0669com

38. Viengchareun S, Zennaro MC, Pascual-Le Tallec L, Lombes M. Brown adipocytes are novel sites of expression and regulation of adiponectin and resistin. FEBS Lett (2002) 532(3):345-50. doi:10.1016/S0014-5793(02)03697-9

39. Bianco AC, McAninch EA. The role of thyroid hormone and brown adipose tissue in energy homoeostasis. Lancet Diabetes Endocrinol (2013) 1(3):250-8. doi:10.1016/S2213-8587(13)70069-X

40. Collins S, Yehuda-Shnaidman E, Wang H. Positive and negative control of Ucp1 gene transcription and the role of beta-adrenergic signaling networks. Int J Obes (Lond) (2010) 34(Suppl 1):S28-33. doi:10.1038/ijo.2010.180

41. Kajimura S, Seale P, Spiegelman BM. Transcriptional control of brown fat development. Cell Metab (2010) 11(4):257-62. doi:10.1016/j. cmet.2010.03.005

42. Gray SL, Dalla Nora E, Backlund EC, Manieri M, Virtue S, Noland RC, et al. Decreased brown adipocyte recruitment and thermogenic capacity in mice with impaired peroxisome proliferator-activated receptor (P465L PPARgamma) function. Endocrinology (2006) 147(12):5708-14. doi:10.1210/ en.2006-0684

43. Petrovic N, Walden TB, Shabalina IG, Timmons JA, Cannon B, Nedergaard J. Chronic peroxisome proliferator-activated receptor gamma (PPARgamma) activation of epididymally derived white adipocyte cultures reveals a population of thermogenically competent, UCP1-containing adipocytes 
molecularly distinct from classic brown adipocytes. J Biol Chem (2010) 285(10):7153-64. doi:10.1074/jbc.M109.053942

44. Herzig S, Long F, Jhala US, Hedrick S, Quinn R, Bauer A, et al. CREB regulates hepatic gluconeogenesis through the coactivator PGC-1. Nature (2001) 413(6852):179-83. doi:10.1038/35093131

45. Puigserver P, Wu Z, Park CW, Graves R, Wright M, Spiegelman BM. A cold-inducible coactivator of nuclear receptors linked to adaptive thermogenesis. Cell (1998) 92(6):829-39. doi:10.1016/S0092-8674(00)81410-5

46. Tiraby C, Tavernier G, Lefort C, Larrouy D, Bouillaud F, Ricquier D, et al. Acquirement of brown fat cell features by human white adipocytes. J Biol Chem (2003) 278(35):33370-6. doi:10.1074/jbc.M305235200

47. Puigserver P, Spiegelman BM. Peroxisome proliferator-activated receptor-gamma coactivator 1 alpha (PGC-1 alpha): transcriptional coactivator and metabolic regulator. Endocr Rev (2003) 24(1):78-90. doi:10.1210/ er.2002-0012

48. Seale P, Kajimura S, Yang W, Chin S, Rohas LM, Uldry M, et al. Transcriptional control of brown fat determination by PRDM16. Cell Metab (2007) 6(1):3854. doi:10.1016/j.cmet.2007.06.001

49. Qiang L, Wang L, Kon N, Zhao W, Lee S, Zhang Y, et al. Brown remodeling of white adipose tissue by SirT1-dependent deacetylation of Ppargamma. Cell (2012) 150(3):620-32. doi:10.1016/j.cell.2012.06.027

50. Cariou B, Charbonnel B, Staels B. Thiazolidinediones and PPARgamma agonists: time for a reassessment. Trends Endocrinol Metab (2012) 23(5):205-15. doi:10.1016/j.tem.2012.03.001

51. Smorlesi A, Frontini A, Giordano A, Cinti S. The adipose organ: white-brown adipocyte plasticity and metabolic inflammation. Obes Rev (2012) 13(Suppl 2):83-96. doi:10.1111/j.1467-789X.2012.01039.x

52. Cousin B, Bascands-Viguerie N, Kassis N, Nibbelink M, Ambid L, Casteilla L, et al. Cellular changes during cold acclimatation in adipose tissues. J Cell Physiol (1996) 167(2):285-9. doi:10.1002/ (SICI) 1097-4652(199605) 167:2<285::AID-JCP12>3.0.CO;2-7

53. Timmons JA, Wennmalm K, Larsson O, Walden TB, Lassmann T, Petrovic N, et al. Myogenic gene expression signature establishes that brown and white adipocytes originate from distinct cell lineages. Proc Natl Acad Sci U S A (2007) 104(11):4401-6. doi:10.1073/pnas.0610615104

54. Walden TB, Hansen IR, Timmons JA, Cannon B, Nedergaard J. Recruited vs. nonrecruited molecular signatures of brown, "brite," and white adipose tissues. Am J Physiol Endocrinol Metab (2012) 302(1):E19-31. doi:10.1152/ ajpendo.00249.2011

55. Seale P, Bjork B, Yang W, Kajimura S, Chin S, Kuang S, et al. PRDM16 controls a brown fat/skeletal muscle switch. Nature (2008) 454(7207):961-7. doi:10.1038/nature07182

56. Sanchez-Gurmaches J, Guertin DA. Adipocytes arise from multiple lineages that are heterogeneously and dynamically distributed. Nat Commun (2014) 5:4099. doi:10.1038/ncomms5099

57. Sanchez-Gurmaches J, Guertin DA. Adipocyte lineages: tracing back the origins of fat. Biochim Biophys Acta (2014) 1842(3):340-51. doi:10.1016/j. bbadis.2013.05.027

58. Sanchez-Gurmaches J, Hung CM, Sparks CA, Tang Y, Li H, Guertin DA. PTEN loss in the Myf5 lineage redistributes body fat and reveals subsets of white adipocytes that arise from Myf5 precursors. Cell Metab (2012) 16(3):348-62. doi:10.1016/j.cmet.2012.08.003

59. Wu J, Bostrom P, Sparks LM, Ye L, Choi JH, Giang AH, et al. Beige adipocytes are a distinct type of thermogenic fat cell in mouse and human. Cell (2012) 150(2):366-76. doi:10.1016/j.cell.2012.05.016

60. Wu J, Cohen P, Spiegelman BM. Adaptive thermogenesis in adipocytes: is beige the new brown? Genes Dev (2013) 27(3):234-50. doi:10.1101/ gad.211649.112

61. Kajimura S, Seale P, Tomaru T, Erdjument-Bromage H, Cooper MP, Ruas $\mathrm{JL}$, et al. Regulation of the brown and white fat gene programs through a PRDM16/CtBP transcriptional complex. Genes Dev (2008) 22(10):1397-409. doi:10.1101/gad.1666108

62. Kajimura S, Seale P, Kubota K, Lunsford E, Frangioni JV, Gygi SP, et al. Initiation of myoblast to brown fat switch by a PRDM16-C/EBP-beta transcriptional complex. Nature (2009) 460(7259):1154-8. doi:10.1038/ nature 08262

63. Thomsom JF, Habeck DA, Nance SL, Beetham KL. Ultrastructural and biochemical changes in brown fat in cold-exposed rats. J Cell Biol (1969) 41(1):312-34. doi:10.1083/jcb.41.1.312
64. Creasey NH, Gray CH. Enzymes concerned in the synthesis of glycogen from glucose in the brown adipose tissue. Biochem J (1951) 50(1):74-81. doi:10.1042/bj0500074

65. Crisan M, Casteilla L, Lehr L, Carmona M, Paoloni-Giacobino A, Yap S, et al. A reservoir of brown adipocyte progenitors in human skeletal muscle. Stem Cells (2008) 26(9):2425-33. doi:10.1634/stemcells.2008-0325

66. Long JZ, Svensson KJ, Tsai L, Zeng X, Roh HC, Kong X, et al. A smooth muscle-like origin for beige adipocytes. Cell Metab (2014) 19(5):810-20. doi:10.1016/j.cmet.2014.03.025

67. Rosenwald M, Perdikari A, Rulicke T, Wolfrum C. Bi-directional interconversion of brite and white adipocytes. Nat Cell Biol (2013) 15(6):659-67. doi: 10.1038/ncb2740

68. Wang QA, Tao C, Gupta RK, Scherer PE. Tracking adipogenesis during white adipose tissue development, expansion and regeneration. Nat Med (2013) 19(10):1338-44. doi:10.1038/nm.3324

69. Lee YH, Petkova AP, Mottillo EP, Granneman JG. In vivo identification of bipotential adipocyte progenitors recruited by beta3-adrenoceptor activation and high-fat feeding. Cell Metab (2012) 15(4):480-91. doi:10.1016/j. cmet.2012.03.009

70. Lee YH, Petkova AP, Konkar AA, Granneman JG. Cellular origins of cold-induced brown adipocytes in adult mice. FASEB J (2015) 29(1):286-99. doi:10.1096/f.14-263038

71. de Jong JM, Larsson O, Cannon B, Nedergaard J. A stringent validation of mouse adipose tissue identity markers. Am J Physiol Endocrinol Metab (2015) 308(12):E1085-105. doi:10.1152/ajpendo.00023.2015

72. Poher AL, Altirriba J, Veyrat-Durebex C, Rohner-Jeanrenaud F. Brown adipose tissue activity as a target for the treatment of obesity/insulin resistance. Front Physiol (2015) 6:4. doi:10.3389/fphys.2015.00004

73. Bartelt A, Heeren J. Adipose tissue browning and metabolic health. Nat Rev Endocrinol (2014) 10(1):24-36. doi:10.1038/nrendo.2013.204

74. Sidossis L, Kajimura S. Brown and beige fat in humans: thermogenic adipocytes that control energy and glucose homeostasis. J Clin Invest (2015) 125(2):478-86. doi:10.1172/JCI78362

75. Carriere A, Jeanson Y, Berger-Muller S, Andre M, Chenouard V, Arnaud E, et al. Browning of white adipose cells by intermediate metabolites: an adaptive mechanism to alleviate redox pressure. Diabetes (2014) 63(10):3253-65. doi:10.2337/db13-1885

76. DiGirolamo M, Newby FD, Lovejoy J. Lactate production in adipose tissue: a regulated function with extra-adipose implications. FASEB J (1992) 6(7):2405-12.

77. Trayhurn P, Alomar SY. Oxygen deprivation and the cellular response to hypoxia in adipocytes - perspectives on white and brown adipose tissues in obesity. Front Endocrinol (2015) 6:19. doi:10.3389/fendo.2015.00019

78. Ro SH, Nam M, Jang I, Park HW, Park H, Semple IA, et al. Sestrin2 inhibits uncoupling protein 1 expression through suppressing reactive oxygen species. Proc Natl Acad Sci U S A (2014) 111(21):7849-54. doi:10.1073/ pnas.1401787111

79. Lettieri Barbato D, Tatulli G, Maria Cannata S, Bernardini S, Aquilano K, Ciriolo MR. Glutathione decrement drives thermogenic program in adipose cells. Sci Rep (2015) 5:13091. doi:10.1038/srep13091

80. Bostrom P, Wu J, Jedrychowski MP, Korde A, Ye L, Lo JC, et al. A PGC1alpha-dependent myokine that drives brown-fat-like development of white fat and thermogenesis. Nature (2012) 481(7382):463-8. doi:10.1038/ nature10777

81. De Matteis R, Lucertini F, Guescini M, Polidori E, Zeppa S, Stocchi V, et al. Exercise as a new physiological stimulus for brown adipose tissue activity. Nutr Metab Cardiovasc Dis (2013) 23(6):582-90. doi:10.1016/j. numecd.2012.01.013

82. Knudsen JG, Murholm M, Carey AL, Bienso RS, Basse AL, Allen TL, et al. Role of IL-6 in exercise training- and cold-induced UCP1 expression in subcutaneous white adipose tissue. PLoS One (2014) 9(1):e84910. doi:10.1371/ journal.pone.0084910

83. Rao RR, Long JZ, White JP, Svensson KJ, Lou J, Lokurkar I, et al. Meteorinlike is a hormone that regulates immune-adipose interactions to increase beige fat thermogenesis. Cell (2014) 157(6):1279-91. doi:10.1016/j. cell.2014.03.065

84. Jedrychowski MP, Wrann CD, Paulo JA, Gerber KK, Szpyt J, Robinson MM, et al. Detection and quantitation of circulating human irisin by tandem mass spectrometry. Cell Metab (2015). doi:10.1016/j.cmet.2015.08.001 
85. Hofmann T, Elbelt U, Stengel A. Irisin as a muscle-derived hormone stimulating thermogenesis - a critical update. Peptides (2014) 54:89-100. doi:10.1016/j.peptides.2014.01.016

86. Raschke S, Elsen M, Gassenhuber H, Sommerfeld M, Schwahn U, Brockmann B, et al. Evidence against a beneficial effect of irisin in humans. PLoS One (2013) 8(9):e73680. doi:10.1371/journal.pone.0073680

87. Lee P, Linderman JD, Smith S, Brychta RJ, Wang J, Idelson C, et al. Irisin and FGF21 are cold-induced endocrine activators of brown fat function in humans. Cell Metab (2014) 19(2):302-9. doi:10.1016/j. cmet.2013.12.017

88. Evans WJ, Morley JE, Argiles J, Bales C, Baracos V, Guttridge D, et al. Cachexia: a new definition. Clin Nutr (2008) 27(6):793-9. doi:10.1016/j. clnu.2008.06.013

89. Argiles JM, Lopez-Soriano FJ, Toledo M, Betancourt A, Serpe R, Busquets S. The cachexia score (CASCO): a new tool for staging cachectic cancer patients. J Cachexia Sarcopenia Muscle (2011) 2(2):87-93. doi:10.1007/ s13539-011-0027-5

90. Petruzzelli M, Schweiger M, Schreiber R, Campos-Olivas R, Tsoli M, Allen J, et al. A switch from white to brown fat increases energy expenditure in cancer-associated cachexia. Cell Metab (2014) 20(3):433-47. doi:10.1016/j. cmet.2014.06.011

91. Kir S, White JP, Kleiner S, Kazak L, Cohen P, Baracos VE, et al. Tumourderived PTH-related protein triggers adipose tissue browning and cancer cachexia. Nature (2014) 513(7516):100-4. doi:10.1038/nature13528

92. Tsoli M, Moore M, Burg D, Painter A, Taylor R, Lockie SH, et al. Activation of thermogenesis in brown adipose tissue and dysregulated lipid metabolism associated with cancer cachexia in mice. Cancer Res (2012) 72(17):4372-82. doi:10.1158/0008-5472.CAN-11-3536

93. Porter C, Herndon DN, Bhattarai N, Ogunbileje JO, Szczesny B, Szabo C, et al. Severe burn injury induces thermogenically functional mitochondria in murine white adipose tissue. Shock (2015) 44(3):258-64. doi:10.1097/ SHK.0000000000000410

94. Sidossis LS, Porter C, Saraf MK, Borsheim E, Radhakrishnan RS, Chao $\mathrm{T}$, et al. Browning of subcutaneous white adipose tissue in humans after severe adrenergic stress. Cell Metab (2015) 22(2):219-27. doi:10.1016/j. cmet.2015.06.022

95. Champigny O, Ricquier D. Effects of fasting and refeeding on the level of uncoupling protein mRNA in rat brown adipose tissue: evidence for diet-induced and cold-induced responses. J Nutr (1990) 120(12):1730-6.

96. Brestoff JR, Artis D. Immune regulation of metabolic homeostasis in health and disease. Cell (2015) 161(1):146-60. doi:10.1016/j.cell.2015.02.022

97. Vegiopoulos A, Muller-Decker K, Strzoda D, Schmitt I, Chichelnitskiy E, Ostertag A, et al. Cyclooxygenase-2 controls energy homeostasis in mice by de novo recruitment of brown adipocytes. Science (2010) 328(5982):1158-61. doi:10.1126/science.1186034

98. Madsen L, Pedersen LM, Lillefosse HH, Fjaere E, Bronstad I, Hao Q, et al. UCP1 induction during recruitment of brown adipocytes in white adipose tissue is dependent on cyclooxygenase activity. PLoS One (2010) 5(6):e11391. doi:10.1371/journal.pone.0011391

99. Forman BM, Tontonoz P, Chen J, Brun RP, Spiegelman BM, Evans RM. 15-Deoxy-delta 12, 14-prostaglandin J2 is a ligand for the adipocyte determination factor PPAR gamma. Cell (1995) 83(5):803-12. doi:10.1016/0092-8674(95)90193-0

100. Pisani DF, Ghandour RA, Beranger GE, Le Faouder P, Chambard JC, Giroud $\mathrm{M}$, et al. The omega6-fatty acid, arachidonic acid, regulates the conversion of white to brite adipocyte through a prostaglandin/calcium mediated pathway. Mol Metab (2014) 3(9):834-47. doi:10.1016/j.molmet.2014.09.003

101. Qiu Y, Nguyen KD, Odegaard JI, Cui X, Tian X, Locksley RM, et al. Eosinophils and type 2 cytokine signaling in macrophages orchestrate development of functional beige fat. Cell (2014) 157(6):1292-308. doi:10.1016/j. cell.2014.03.066

102. Lee MW, Odegaard JI, Mukundan L, Qiu Y, Molofsky AB, Nussbaum JC, et al. Activated type 2 innate lymphoid cells regulate beige fat biogenesis. Cell (2015) 160(1-2):74-87. doi:10.1016/j.cell.2014.12.011

103. Brestoff JR, Kim BS, Saenz SA, Stine RR, Monticelli LA, Sonnenberg GF, et al. Group 2 innate lymphoid cells promote beiging of white adipose tissue and limit obesity. Nature (2015) 519(7542):242-6. doi:10.1038/nature14115
104. Kong X, Banks A, Liu T, Kazak L, Rao RR, Cohen P, et al. IRF4 is a key thermogenic transcriptional partner of PGC-1alpha. Cell (2014) 158(1):69-83. doi:10.1016/j.cell.2014.04.049

105. Ricquier D, Nechad M, Mory G. Ultrastructural and biochemical characterization of human brown adipose tissue in pheochromocytoma. J Clin Endocrinol Metab (1982) 54(4):803-7.

106. Bouillaud F, Villarroya F, Hentz E, Raimbault S, Cassard AM, Ricquier D. Detection of brown adipose tissue uncoupling protein mRNA in adult patients by a human genomic probe. Clin Sci (Lond) (1988) 75(1):21-7. doi: $10.1042 / \operatorname{cs} 0750021$

107. Huttunen P, Hirvonen J, Kinnula V. The occurrence of brown adipose tissue in outdoor workers. Eur J Appl Physiol Occup Physiol (1981) 46(4):339-45. doi:10.1007/BF00422121

108. Heaton JM. The distribution of brown adipose tissue in the human. J Anat (1972) 112(Pt 1):35-9.

109. Cypess AM, Lehman S, Williams G, Tal I, Rodman D, Goldfine AB, et al. Identification and importance of brown adipose tissue in adult humans. $N$ Engl J Med (2009) 360(15):1509-17. doi:10.1056/NEJMoa0810780

110. Virtanen KA, Lidell ME, Orava J, Heglind M, Westergren R, Niemi T, et al. Functional brown adipose tissue in healthy adults. N Engl J Med (2009) 360(15):1518-25. doi:10.1056/NEJMoa0808949

111. van Marken Lichtenbelt WD, Vanhommerig JW, Smulders NM, Drossaerts JM, Kemerink GJ, Bouvy ND, et al. Cold-activated brown adipose tissue in healthy men. N Engl J Med (2009) 360(15):1500-8. doi:10.1056/ NEJMoa0808718

112. Saito M, Okamatsu-Ogura Y, Matsushita M, Watanabe K, Yoneshiro T, NioKobayashi J, et al. High incidence of metabolically active brown adipose tissue in healthy adult humans: effects of cold exposure and adiposity. Diabetes (2009) 58(7):1526-31. doi:10.2337/db09-0530

113. Shinoda K, Luijten IH, Hasegawa Y, Hong H, Sonne SB, Kim M, et al. Genetic and functional characterization of clonally derived adult human brown adipocytes. Nat Med (2015) 21(4):389-94. doi:10.1038/nm.3819

114. Sharp LZ, Shinoda K, Ohno H, Scheel DW, Tomoda E, Ruiz L, et al. Human BAT possesses molecular signatures that resemble beige/brite cells. PLoS One (2012) 7(11):e49452. doi:10.1371/journal.pone.0049452

115. Cypess AM, White AP, Vernochet C, Schulz TJ, Xue R, Sass CA, et al. Anatomical localization, gene expression profiling and functional characterization of adult human neck brown fat. Nat Med (2013) 19(5):635-9. doi: $10.1038 / \mathrm{nm} .3112$

116. Jespersen NZ, Larsen TJ, Peijs L, Daugaard S, Homoe P, Loft A, et al. A classical brown adipose tissue mRNA signature partly overlaps with brite in the supraclavicular region of adult humans. Cell Metab (2013) 17(5):798-805. doi:10.1016/j.cmet.2013.04.011

117. Esteve D, Boulet N, Volat F, Zakaroff-Girard A, Ledoux S, Coupaye M, et al. Human white and brite adipogenesis is supported by MSCA1 and is impaired by immune cells. Stem Cells (2015) 33(4):1277-91. doi:10.1002/ stem.1916

118. Xue R, Lynes MD, Dreyfuss JM, Shamsi F, Schulz TJ, Zhang H, et al. Clonal analyses and gene profiling identify genetic biomarkers of the thermogenic potential of human brown and white preadipocytes. Nat Med (2015) 21(7):760-8. doi:10.1038/nm.3881

119. Mund RA, Frishman WH. Brown adipose tissue thermogenesis: beta3-adrenoreceptors as a potential target for the treatment of obesity in humans. Cardiol Rev (2013) 21(6):265-9. doi:10.1097/CRD.0b013e31829cabff

120. Bordicchia M, Pocognoli A, D’Anzeo M, Siquini W, Minardi D, Muzzonigro G, et al. Nebivolol induces, via beta3 adrenergic receptor, lipolysis, uncoupling protein 1 , and reduction of lipid droplet size in human adipocytes. J Hypertens (2014) 32(2):389-96. doi:10.1097/ HJH.0000000000000024

121. Yoneshiro T, Ogawa T, Okamoto N, Matsushita M, Aita S, Kameya T, et al. Impact of UCP1 and beta3AR gene polymorphisms on age-related changes in brown adipose tissue and adiposity in humans. Int J Obes (Lond) (2013) 37(7):993-8. doi:10.1038/ijo.2012.161

122. Cypess AM, Weiner LS, Roberts-Toler C, Franquet Elia E, Kessler SH, Kahn PA, et al. Activation of human brown adipose tissue by a beta3-adrenergic receptor agonist. Cell Metab (2015) 21(1):33-8. doi:10.1016/j. cmet.2014.12.009 
123. Fruchart JC. Selective peroxisome proliferator-activated receptor alpha modulators (SPPARMalpha): the next generation of peroxisome proliferator-activated receptor alpha-agonists. Cardiovasc Diabetol (2013) 12:82. doi:10.1186/1475-2840-12-82

124. Blackburn GL. From bench to bedside: novel mechanisms and therapeutic advances through the development of selective peroxisome proliferator-activated receptor gamma modulators. Am J Clin Nutr (2010) 91(1):251S-3S. doi:10.3945/ajcn.2009.28449A

125. Broeders EP, Nascimento EB, Havekes B, Brans B, Roumans KH, Tailleux A, et al. The bile acid chenodeoxycholic acid increases human brown adipose tissue activity. Cell Metab (2015) 22(3):418-26. doi:10.1016/j.cmet.2015.07.002
Conflict of Interest Statement: The authors declare that the research was conducted in the absence of any commercial or financial relationships that could be construed as a potential conflict of interest.

Copyright (C) 2015 Jeanson, Carrière and Casteilla. This is an open-access article distributed under the terms of the Creative Commons Attribution License (CC BY). The use, distribution or reproduction in other forums is permitted, provided the original author(s) or licensor are credited and that the original publication in this journal is cited, in accordance with accepted academic practice. No use, distribution or reproduction is permitted which does not comply with these terms. 